\title{
A NEW PATTERN FOR URBAN RENEWAL
}

\section{David M. Walker*}

Urban renewal is a necessary concomitant of urban civilization. Since the forces which determine urban location tend also to perpetuate it, the ravages of time and the inadequacies of planning must be repaired by renewing the city instead of removing the population. But urban renewal does not regenerate cities pursuant to an immutable law. The forces of renewal do not inevitably prevail over the forces of decay. Archaeological investigation of ancient urban cultures reveals on the one hand successive efforts at renewal, while proving on the other that cities-even great ones-do not always survive.

Technology has marvellously increased our ability to deal with physical problems of environment. Yet the unsolved problems of modern urban living are so close about us we can reach out and touch a surfeit of them at any given hour. They are so familiar their recital would be trite. Urban renewal is the instrument designed to combine the forces of government with those of private enterprise for the resolution of these problems. It is a good instrument, susceptible of improvement but nevertheless capable of doing the job if we use it well.

There is growing recognition of the permanent or continuous nature of urban renewal. This program, improved in the light of experience by Congress, by state legislatures and city councils, and by those who administer it, should be just as much a part of municipal life as zoning, traffic engineering, or fire prevention-in fact, with our present urban problems and our present knowledge about their solution, we know that these other accepted facets of municipal government are not fully effective except in combination with urban renewal.

A recognition of the continuous nature of urban renewal should rest upon recognition of the basic reasons for its continuity. Fortunately, our ability to plan, at least to meet today's problems, has increased as our recognition of the value of planning has increased. Nevertheless, the creativity of individual ingenuity, which is one of the great benefits of a free society, will always outpace organized planning. Therefore, continuity in urban renewal does not mean increasing government intervention in property ownership; it means using the present urban renewal process, with government intervention held to a minimum, for the constant refurbishing and reshaping of our population centers to meet constantly changing circumstances.

At the present time, the city core is the center of the urban renewal effort. As the cities have grown outward into the suburbs, slum areas of the older central city have worsened and spread, creating an immediate need for the slum clearance

- LL.D. 1954, Temple University; D.H.L. 1960, Duquesne University- Commissioner, Urban Renewal Administration, Housing and Home Finance Agency. Exceutire Director, Redevelopment Authority, City of Philadelphia, 1946-51; Secretary of Labor and Inidustry, State of Pennsylvania, 1951-55. 
aspects of the program. When urban renewal is viewed in the light of more recent legislation as an attack on the problems of the city as a whole, not just slum neighborhoods, the central city still requires immediate attention because of its age and because of its overriding importance to all inhabitants of the entire urban-suburban complex. And yet, if we can depend on history to teach us any lessons for tomorrow, we must conclude that inevitably the suburban rings around our central cities will be inadequate for, or incompatible with, twenty-first century living, and the urban renewal process will be moving into the suburbs before we are through with the central city. And then, unless we plan to abandon our cities, certainly before we are through with the suburbs, we will be back renewing the central city, if, indeed, we have ever discontinued there.

Urban renewal is just now falling into the pattern that it must adopt to meet the challenge of maintaining population centers compatible with the changes in modes of living. The program began with slum clearance in 1949. ${ }^{2}$ The Housing Act of $1954^{2}$ developed the concept of urban renewal, including rehabilitation, blightprevention, and the concept of attacking on a broad front all of the city's housing problems as an integral part of urban renewal. As the meaning of this transition from a slum clearance to an urban renewal program became clear, in the Housing Act of $1959^{3}$ the concept of a community-wide program was written into the law with the provision for a Community Renewal Plan.

In my opinion, as those engaged in urban renewal gain experience with community-wide planning under a Community Renewal Plan, there will develop, largely by administration but partly by legislation, a technique in urban renewal which at this reading must be called new. Cities will no longer have urban renewal projects. The city will have only one project, which will embrace the entire city. Cities will no longer requisition funds and make plans project by project. A city will proceed with its one large project for renewal, and will draw down periodic payments that will apply to the entire job against a budget that has been established for a ten-or twenty-year program.

A logical deduction from the consideration of urban renewal as a continuous process would be that the budgeted amount for a Community Renewal Plan would have certain characteristics of an open-end mortgage, being in effect more of a current estimate than a limitation on expense. This may well prove to be the case. However, the development of the Community Renewal Plan has enough immediate problems without borrowing further from the future. This reference to the Community Renewal Plan illustrates the fact about urban renewal that strikes me most forcefully: it is only beginning.

\footnotetext{
' 63 Stat. 413,42 U.S.C. 5 I 44 I (1958).

268 Stat. 622,42 U.S.C. 51450 (1958).

${ }^{3} 73$ Stat. 672, 42 U.S.C.A. 5 1453 (Supp. 1959).
} 